\title{
Estudo de caso sobre o apoio institucional na gestão federal da Atenção Básica no Brasil
}

\author{
Case study on institutional support in the federal management of \\ Primary Health Care in Brazil
}

Francini Lube Guizardi', Leonardo Passeri', Ana Silvia Pavani Lemos', Felipe Rangel de Souza Machado²

DOI: $10.1590 / 0103-1104201912203$

RESUMO $\mathrm{O}$ artigo analisou as potencialidades e os limites da função apoio institucional como estratégia para democratizar a gestão federal de políticas de saúde, a partir do campo de ação da Política Nacional de Atenção Básica, no período compreendido entre 2011 e 2015. A pesquisa adotou como perspectiva metodológica a epistemologia qualitativa, com o emprego de entrevistas em profundidade, grupos focais e observação participante. Os resultados foram depurados por meio de dois ciclos interpretativos: no primeiro, mapearam-se atribuições, modos de inserção, estratégias de intervenção e organização do processo de trabalho; no segundo, exploraram-se os padrões institucionais presentes na experiência. O referencial teórico do estudo foi baseado na abordagem ergológica e no conceito de instituição, conforme tradição do institucionalismo francês. Observou-se que a estratégia de apoio institucional engendrou e fortaleceu redes sociotécnicas, produzindo maior acesso a recursos e compartilhamento do processo decisório da política pública, com potenciais relevantes de intervir em sua democratização. Contudo, a necessidade de implementação de programas prioritários requisita ser mais bem equacionado no desenho dessa estratégia de gestão.

PALAVRAS-CHAVE Atenção Primária à Saúde. Gestão em saúde. Organização e administração. Democracia.

\begin{abstract}
The article analyzes the potentialities and the limits of the institutional support function as a strategy to democratize the management of health policies. This aim was investigated in the National Policy of Primary Health Care, in the period between 2011 and 2015. Qualitative epistemology was adopted as methodological perspective, with the use of in-depth interviews, focus groups, and participant observation. The results were assessed through two interpretative cycles. In the first one, of a descriptive nature, we seek to map out assignments, modes of insertion, intervention strategies, and organization of the institutional support work process. In the second cycle, of an analytical nature, the institutional patterns present in this experiment were explored. The theoretical framework of the study was based on the ergological approach and the concept of institution, according to the tradition of French institutionalism. We observed that the institutional support strategy generated and strengthened socio-technical networks articulated in function of the National Policy of Primary Health Care. However, the necessity of implementation of priority programs demands it to be better considered in the design of this management strategy.
\end{abstract}

1 Fundação Oswaldo Cruz (Fiocruz) - Brasília (DF), Brasil.

francini.guizardi@fiocruz.br

2 Fundação Oswaldo Cruz (Fiocruz) - Rio de Janeiro (RJ), Brasil.
KEYWORDS Primary Health Care. Health management. Organization and administration. Democracy. 


\section{Introdução}

A função Apoio Institucional (AI) consiste em uma tecnologia de intervenção na organização do trabalho, que visa ampliar a democracia institucional na produção de saúde ${ }^{\mathbf{1 - 4}}$. A partir do ano de 2011, a função AI foi incorporada na gestão federal brasileira de modo amplo como uma estratégia relevante para implementação de políticas de saúde prioritárias, direcionadas à qualificação de redes de atenção no Sistema Único de Saúde (SUS) ${ }^{1,5,6}$. Essa inserção tem como contexto político-institucional o enfrentamento de alguns problemas históricos desse sistema, em particular, sua elevada fragmentação e as dificuldades de comunicação e ação coordenada entre entes federados 7,8 . O recurso à função AI é, dessa forma, justificado como uma alternativa aos modos hegemônicos de gestão pública em saúde, que se revelaram ineficientes na resolução de um conjunto de questões centrais à consolidação do SUS ${ }^{2}$.

A inserção do AI na qualificação de redes de atenção apresentou características diferentes daquelas observadas no início da utilização dessa metodologia ${ }^{3,9}$. A implementação de estratégias e dispositivos do método ocorreu, inicialmente, na década de 2000, na cidade de Campinas/ SP, sendo, em seguida, adotada em outras cidades, como "Belo Horizonte/MG, Sobral/ CE, Diadema/SP, Amparo/SP, São Bernardo/SP, Recife/PE, Aracaju/SE, Vitória/ES”(896).

Já em 2003, o AI foi incorporado pela Secretaria Executiva do Ministério da Saúde (SE/MS), em um movimento que adquiriu dois enfoques: o fortalecimento da gestão descentralizada e cooperativa do SUS e a mudança dos modelos de gestão e atenção em serviços e sistemas de saúde ${ }^{4}$. Como salientam Pereira Junior e Campos 7 , havia então um contexto propício à temática da democratização, o que auxiliou a expansão da metodologia também em experiências estaduais, como no caso do Rio de Janeiro e da Bahia ${ }^{4,10-12}$. Ainda assim, esse movimento inicial de implementação permaneceu localizado, quando situado no conjunto da política nacional de saúde.
A partir de 2011, observa-se um cenário distinto. Nesse segundo momento, o AI foi mobilizado amplamente na articulação interna do MS, visando tanto interferir na cultura organizacional da instituição, marcada pela fragmentação e desarticulação entre setores, quanto qualificar as relações federativas estabelecidas com demais instâncias gestoras do SUS, historicamente verticalizadas, e baseadas em uma lógica prescritivo-normativa, de caráter programático, que tinham na indução financeira a principal forma de coordenação nacional da política de saúde ${ }^{1,6,13}$. Um contexto que revela o acúmulo crítico propiciado pelo Pacto pela Saúde, não obstante suas dificuldades de operacionalização ${ }^{\mathbf{1 4}}$. Ambos os propósitos não diferem em substância daqueles que marcaram o contexto inicial de inserção do AI na gestão federal, a diferença reside, outrossim, na extensão do recurso a essa metodologia e no investimento político empregado em sua consecução. Assim, se o AI, desde o início de sua configuração, esteve associado a experiências municipais fortemente ancoradas na Atenção Básica (AB), apenas a partir de 2011 pode-se observar sua presença na condução federal da Política Nacional de Atenção Básica (PNAB). Na primeira revisão da política, publicada em 2012, o AI surge claramente como um mecanismo e uma atribuição das diferentes instâncias de governo que compartilham a responsabilidade sanitária pela condução do SUS.

O Programa Nacional de Melhoria do Acesso e da Qualidade da Atenção Básica (PMAQ-AB), que objetiva fortalecer a cultura de avaliação e incentivar o aperfeiçoamento dos serviços ofertados, incorporou o AI como uma das dimensões de gestão a ser aferida, tanto na autoavaliação realizada pelas equipes, como no procedimento de avaliação externa ${ }^{15,16}$. Essa inserção representou um importante veículo de disseminação e indução da metodologia em âmbito nacional, em razão da abrangência e da relevância adquirida pelo programa.

Destarte, $o$ artigo apresenta parte dos resultados de uma pesquisa que teve como objetivo descrever e analisar o processo político de 
inserção do $\mathrm{AI}$ na $\mathrm{AB}$ desenvolvido no âmbito na Coordenação Geral de Gestão da Atenção Básica/Departamento de Atenção Básica/ Secretaria de Atenção à Saúde do Ministério da Saúde (CGGAB/DAB/SAS/MS). Nela, busca-se identificar as potencialidades e os limites da função AI como estratégia para democratizar a gestão de políticas de saúde, a partir do campo de ação da PNAB, no período compreendido entre 2011 e 2015. Neste texto, aborda-se, especificamente, a implementação do AI na agenda do DAB/MS, com foco na identificação de aspectos centrais da organização do processo de trabalho dos apoiadores, no mapeamento das atribuições, modos de inserção e estratégias de intervenção utilizadas.

\section{Métodos}

O desenho do estudo inscreve-se no campo da epistemologia qualitativa, assumindo como princípios o caráter construtivo, interpretativo e processual da produção de conhecimento científico; a legitimidade do singular nesta produção e a centralidade dos processos de diálogo e comunicação na tarefa de compreensão pertinente às ciências humanas e sociais ${ }^{17}$. A pesquisa realizada adotou como perspectiva metodológica, em consonância com esse referencial, a produção de sentidos dos sujeitos, a partir da qual se busca apreender o processo de inserção política do AI na PNAB. Nessa tarefa, a configuração adequada do cenário de pesquisa constituiu uma questão central, cujo processo descreve-se a seguir. Respeitando as normativas vigentes a pesquisa foi registrada na Plataforma Brasil, sob inscrição CAAE: 34349314.4.0000.5650, parecer de aprovação ${ }^{0}$ 1.205.893.

Em setembro de 2015, iniciou-se o contato com a CGGAB/DAB/MS, lócus do estudo. O trabalho de AI configurava-se então com duas atribuições distintas: Apoiadores Centralizados (AIC) e Apoiadores Descentralizados (AID). Os primeiros residiam em Brasília e atuavam prioritariamente no MS, dividindo-se entre a condução de frentes temáticas e pautas específicas relativas à $\mathrm{PNAB}$, acrescidas de ações de caráter pontual nos territórios que apoiavam, com periodicidade irregular. Por sua vez, os AID residiam e trabalhavam principalmente in loco, ocupando-se da articulação, intervenção e acompanhamento nos territórios.

Em novembro, iniciou-se o trabalho de campo. Foram feitas nove reuniões com a equipe da coordenação entre novembro de 2015 e julho de 2016 , que geraram dados de observação participante e registros em áudio. Nesse período, realizaram-se dois Grupos Focais (GF) com os AIC da CGGAB. Além das atividades em reuniões de colegiado, a observação participante incluiu o VI e VII Fóruns Nacionais de Gestão da Atenção Básica, ocorridos em outubro de 2015 e outubro de 2016, em Brasília (DF). Neste último evento, realizou-se um GF com a participação de seis profissionais que atuaram como AID, compondo uma amostra por conveniência, em razão da presença no seminário.

Optou-se também pela realização de entrevistas em profundidade com informantes-chave, a fim de aprofundar aspectos já mapeados e explorar melhor a singularidade das experiências individuais. A atividade ocorreu entre maio e junho de 2017 , com a realização de 23 entrevistas com dirigentes do DAB/MS (2), AIC (17) e AID (4). Nos trechos de falta, essas referências aparecem indicando a categoria, se Dirigente (D) Apoiador Institucional Centralizado (AIC) ou Apoiador Institucional Descentralizado (AID) e número sequencial, conforme inserção da entrevista no banco de dados. As entrevistas buscaram investigar a trajetória de formação e atuação profissional dos apoiadores, a organização do AI na CGGAB e os principais aspectos de suas experiências com os diferentes estados, para os quais haviam sido designados, em distintos momentos do período em estudo.

O material produzido no trabalho de campo foi integralmente transcrito e codificado com a utilização do software Atlas.ti. Recorreuse a quatro categorias operacionais prévias: perfil dos apoiadores; trajetória profissional; 
formação/qualificação profissional; experiência do AI na CGGAB; apoio integrado do MS. Estas se desdobraram em outras 29 subcategorias.

\begin{tabular}{|c|c|}
\hline CATEGORIA & SUBCATEGORIAS \\
\hline \multirow[t]{4}{*}{ Perfil } & Sexo e idade \\
\hline & Tempo de Trabalho na CGGAB \\
\hline & Vínculo profissional com o MS \\
\hline & Região de Origem \\
\hline \multirow[t]{5}{*}{ Trajetória profissional } & Experiências de trajetória ligadas à Graduação \\
\hline & Trajetória profissional pregressa \\
\hline & Influências da trajetória no exercício do apoio \\
\hline & Inserção na CGGAB/DAB \\
\hline & Motivação para o trabalho como Al \\
\hline \multirow[t]{5}{*}{ Formação/qualificação profissional } & Educação formal \\
\hline & Competências para o trabalho como Al \\
\hline & Educação Permanente no trabalho \\
\hline & Aprendizagem no trabalho \\
\hline & Gestão do Conhecimento e da informação \\
\hline \multirow[t]{9}{*}{ Experiência do apoio institucional } & Organização do Processo de Trabalho - AC \\
\hline & Organização do Processo de Trabalho - AD \\
\hline & Prescrição do Trabalho do Al \\
\hline & Trabalho Real do Al \\
\hline & Relação com a CGGAB (AD) \\
\hline & Relação Interfederativa \\
\hline & Relação Intraministerial (MS) \\
\hline & Relação Intrassetorial (DAB) \\
\hline & Avanços Possibilitados Pelo Al \\
\hline \multirow[t]{3}{*}{ Apoio integrado } & Ações Desenvolvidas \\
\hline & Histórico \\
\hline & Relação com o DAB/MS \\
\hline
\end{tabular}

Fonte: Elaboração própria.

O presente artigo apresenta resultados obtidos por meio da categoria 'experiência do AI na CGGAB', composta pelos seguintes temas: organização do processo de trabalho do AI centralizado e descentralizado; prescrição do trabalho de AI; trabalho real no AI; relação interfederativa; relação intraministerial (MS); relação intrassetorial (DAB); avanços possibilitados pelo AI.

Os resultados de pesquisa foram depurados por meio de dois ciclos interpretativos. No primeiro, de caráter descritivo, buscou-se 
mapear atribuições, modos de inserção, estratégias de intervenção, e organização do processo de trabalho do AI na CGGAB/DAB/ MS. No segundo ciclo, de caráter analítico, foram explorados os padrões institucionais presentes na experiência. O referencial teórico do estudo foi baseado na abordagem ergológica e no conceito de instituição, entendido de modo amplo como práticas e identidades sociais, em seus diferentes graus de formalização, que possibilitam desvendar a estruturação das situações políticas. Nessa apreensão, as instituições configuram o campo de forças que regula o conflito social, não sendo, portanto, estritamente uma variável de análise, uma vez que respondem pela mediação entre as ações e estratégias dos atores sociais em situações políticas historicamente determinadas ${ }^{\mathbf{1 8}}$.

Foram realizadas duas atividades de validação dos resultados e análises com os sujeitos da pesquisa. Na primeira, uma oficina organizada em novembro de 2017, contou-se com a presença de 10 apoiadores da CGGAB. Nela, foram apresentados e discutidos os resultados e produtos parciais da pesquisa, concernentes ao primeiro ciclo. Em dezembro desse mesmo ano, ocorreu o seminário final, com expressiva participação da equipe de apoiadores institucionais da CGGAB/DAB/MS (18 pessoas) e de pesquisadores convidados (3), com foco nos resultados do segundo ciclo de análise.

Figura 1. Percurso metodológico da pesquisa

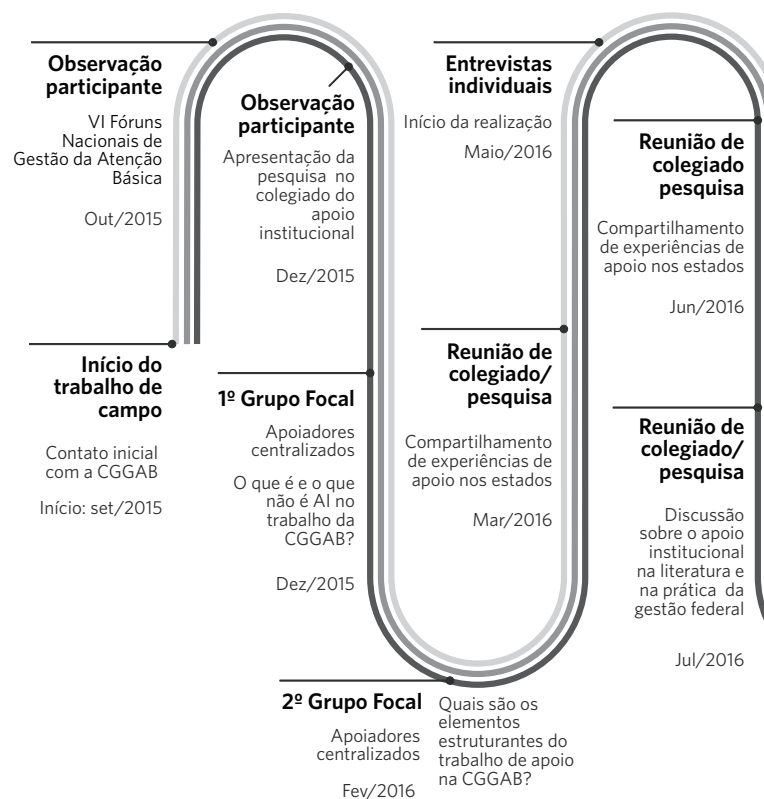

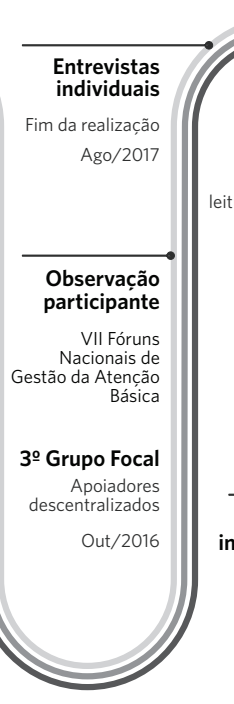
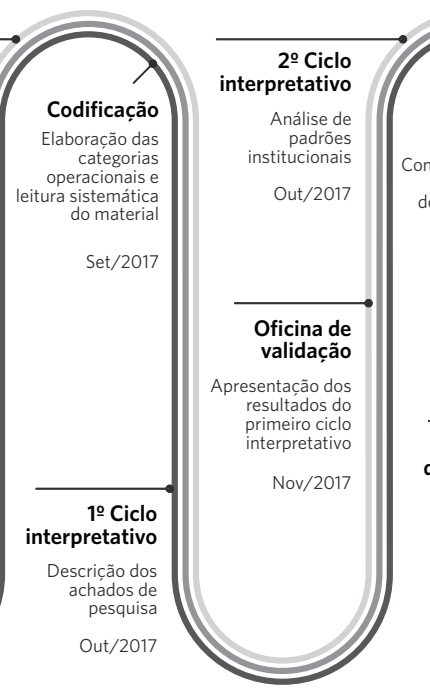

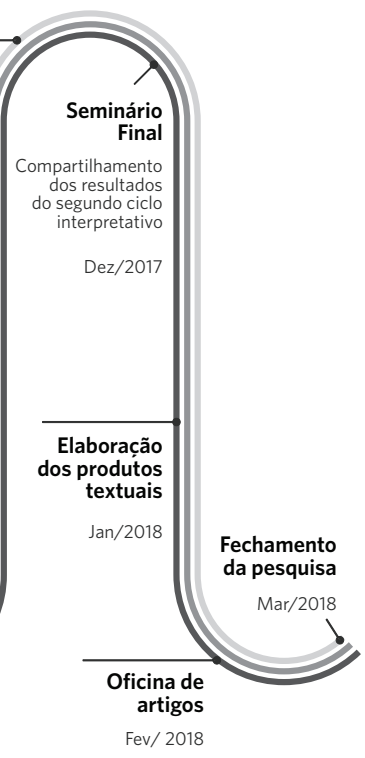

Fonte: Elaboração própria. 


\section{Resultados: descrição da experiência de AI na CGGAB/MS}

A inserção do AI no DAB, em 2011, teve como contexto político institucional a heterogeneidade da implementação da PNAB no Brasil, com a identificação de muitos territórios em que o processo se apresentava lento e fragilizado. A principal explicação para esse cenário remetia às dificuldades concretas da política de abarcar realidades e especificidades locorregionais, resultando disso um conjunto diversificado de obstáculos em sua implementação, que evidenciavam os limites da estratégia de indução financeira e normativa, usualmente empregadas na coordenação nacional das políticas de saúde.

As experiências pessoais prévias de AI dos responsáveis por funções dirigentes no DAB foram determinantes na adoção da estratégia, que se inicia juntamente com a nova gestão do governo federal.

Eu e várias outras pessoas, né? [...] se aproxima dessa temática do apoio antes de estar no MS. [...] Eu, por exemplo, já fui apoiador institucional de equipe de Atenção Básica [...] essas experiências prévias [...] influenciaram muito o que foi levar, ou defender, ou estruturar apoio institucional no MS, no DAB, num dado momento. (D 2).

O AI foi articulado como uma ferramenta de gestão, porém, como um recurso/estratégia adicional. Nesse sentido, embora incidisse nas práticas e relações federativas da gestão praticada pelo departamento, com a perspectiva de apoiar os estados e municípios a partir de uma relação de cooperação e não de supervisão, o AI não alcançou a condição de modelo de gestão. Esse aspecto é evidenciado pela dupla função dos trabalhadores da CGGAB, que atuavam tanto como AIC como também eram referência técnica de uma ou mais frentes de ação programática do departamento. Esta segunda atribuição representou uma linha de continuidade no modo histórico de atuação dos técnicos no âmbito do MS, caracterizando-se por seu direcionamento interno, situado na estrutura complexa e verticalizada dessa organização.

A PNAB tem uma dimensão gigantesca. Então, tem uma série de questões técnicas e políticas que se tratam internamente que às vezes implicam na agenda do Al propriamente dito, [...] o pessoal que trabalha com as frentes, né? As frentes de trabalho que estão colocadas aqui pra CGGAB, que demandam de mais tempo que o próprio apoio institucional. (AIC 7).

Encontraram-se três principais objetivos traçados para o AI na gestão federal da AB. O primeiro buscava a aproximação da gestão federal das realidades e especificidades locorregionais, a partir do estabelecimento de contato e diálogo contínuo com estados e municípios, viabilizando a produção de uma cartografia territorial (geográfica, cultural e social) que qualificasse a condução da política e o suporte necessário à adoção dos programas estratégicos.

Lembrar um pouco de como era aquilo no território e compreender algumas questões que eles traziam [...] pensar que aquela política que foi desenhada ela tinha que, muito, ser melhorada ainda, aprimorada para ela funcionar da forma que a gente esperava. (AIC 12).

Esse aspecto remete diretamente ao segundo objetivo identificado, que era facilitar a descentralização e implementação das agendas prioritárias da gestão federal da PNAB.

A metodologia, ela era desenvolvida conforme cada política ou cada frente de ação, digamos assim, [...] Cada tema daqui da AB, então você tem PMAQ, você tem e-SUS, você tem... E vamos lá fazer as agendas no local com base nesses temas. (AIC 17).

O principal recurso adotado foi o estabelecimento de atores de referência para os 
interlocutores, que deveriam identificar e prover respostas particularizadas às demandas e necessidades de estados e municípios.

Do que eu entendo, do que é alinhamento nosso aqui no grupo, é a questão de ser assim, uma pessoa de referência para as necessidades do território dentro do departamento. (AIC 15).

Nesse sentido, o AI constituiu uma estratégia central para ampliar a adesão a programas estratégicos, como o PMAQ-AB, o e-SUS AB, o Requalifica Unidade Básica de Saúde (UBS), a UBS fluvial, a academia da saúde, os Núcleos de Apoio à Saúde da Família (Nasf), o Telessaúde, o Programa Mais Médicos e o Consultório na Rua, entre outros. Visava-se, com esses delineamentos, um terceiro objetivo, de fortalecimento de atores locais na implementação da PNAB, incentivando, inclusive, estados e municípios a adotarem o AI como estratégia de gestão.

Foram identificados três diferentes arranjos organizativos do AI da CGGAB no período em análise. O primeiro, vigente entre 2011 e 2014, caracterizava-se por duplas e trios de apoiadores responsáveis por um determinado conjunto de estados (entre 2 e 4). Em relação a tal arranjo, o principal limite encontrado foi a dificuldade de estabelecer contato contínuo e manutenção de agendas com todos os estados e municípios apoiados, o que gerou a percepção de um apoio 'superficial'.

Aí a gente se reorganiza dividindo o grupo que tinha pelos estados, ainda não tinha condição de ficar uma pessoa por estado. Então, nós nos dividíamos com mais de dois. [...] onde nós ficamos com duplas para um bloco de estados. (AIC 16).

Na segunda configuração, organizada no ano de 2014, cada Apoiador Centralizado (AC) passou a apoiar individualmente um estado, ou, quando necessário, mais de um. "Depois novamente, aí já mais no ano passado [...] se redivide. $E$ a proposta seria cada um ficar com um estado" (AIC 16). A distribuição dos AC pelos estados era definida de modo compartilhado, entre equipe e coordenação da CGGAB, considerando interesses dos apoiadores, perfil ou necessidade político-institucional identificada, havendo significativa flexibilidade para alterações, conforme avaliação do processo das intervenções.

No período entre 2011 e 2013, ocorreu a implementação do Apoio Descentralizado (AID), como parte do movimento mais geral de estruturação do apoio integrado. Com isso, AIC atuava conjuntamente com o AID naqueles estados em que a estratégia estava implantada, o que gerou conflitos.

\begin{abstract}
Mas só para complementar um pouquinho desse formato inicial, que era o centralizado com descentralizado, havia muita divergência também [...], gerava um conflito, porque como era uma equipe de apoiadores, só que a gente estava descentralizado [...] quem estava aqui entrava em contato direto lá sem nem falar com o apoiador, isso era muito comum. Porém a gente pautava muito isso, 'cara, eu sou daí da CGGAB, como é que a própria CGGAB entra em contato, faz combinações sem combinar com a gente?'. (G 3).
\end{abstract}

Por fim, houve uma terceira composição, estabelecida ainda em 2014, resultante do entendimento de que não havia necessidade de atuação compartilhada em um mesmo território. Os estados que contavam com um AID deixaram de ter como referência um AIC. No decorrer do período estudado, todos os estados do País foram apoiados pelo arranjo do AIC, e sete tiveram AID.

$\mathrm{Na}$ mudança do apoio, [...] o estado que tem apoiador descentralizado não tem centralizado. [...] Por exemplo, uma pessoa apoiava dois estados, mas nunca tinha duas pessoas com um estado. (D 1). 
Figura 2. Arranjos organizativos do AI na CGGAB

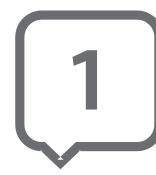

Duplas e trios de apoiadores institucionais responsáveis por um conjunto de estados. Início da estratégia de apoio descentralizado, como parte do apoio integrado do MS

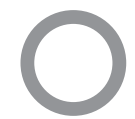

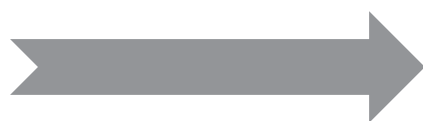

2011

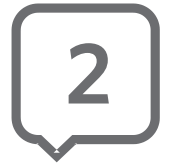

Cada estado tinha apenas um apoiador centralizado de referência.

O apoiador descentralizado atuava em parceria com o apoiador centralizado em seu estado de referência

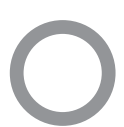

.
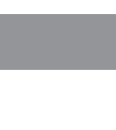

2014

Cada estado tinha apenas um apoiador institucional (centralizado ou descentralizado) de referência ereferencia
O alcance mais restrito do AID decorreu, segundo os entrevistados, de dificuldades operacionais de implantação da estratégia, relacionadas com a identificação e seleção de profissionais com perfil adequado, com a organização do processo de trabalho dos diferentes apoiadores no território, acrescidas de limitações de estrutura e suporte logístico.

Era bem difícil preencher com o perfil que ele [Diretor] entendia que era importante naquele momento [...] foi uma estratégia que nunca vingou muito bem, ou nunca se resolveu muito bem. (D 1).

Infere-se, ademais, que esse resultado também tenha relação com a curta vigência do projeto, e com as resistências internas que mobilizou.

$\mathrm{Na}$ verdade, constante foi a instabilidade, constantemente a gente estava instável. (G 3).

Muito interessante no começo, porque o próprio $D A B$ e o próprio Ministério não estava pronto para ofertar o mínimo de ferramentas, eu lembro da angústia da gente inicialmente para trabalhar com as políticas [...] a gente assim, ia tocar as oficinas, era praticamente mendigar material [...]. Depois surgiu a necessidade do Dropbox, foi tudo se costurando, [...] a gente fez uma rede colaborativa. [...] Tinha reunião de colegiado [...] a questão das ferramentas, acho que foi algo que a gente mais avançou, porque a maioria dos apoiadores [do apoio integrado], quando viu o trabalho do apoio do DAB nosso, falava: 'cara, vocês têm acesso a tudo isso?' A gente começou a ter acesso a sistemas, está entendendo? Como é que a gente vai estar instrumentalizado para apoiar? Claro que perpassa por uma questão pedagógica, mas precisa de ferramentas concretas, principalmente as políticas. (G 3 ).

Tanto o AIC quanto o AID tinham caráter generalista, ou seja, o apoio ofertado aos estados e municípios era relacionado com as principais frentes da PNAB, mas também com as políticas transversais do SUS. "A gente na CGGAB tem um leque muito grande de ações, vai para tudo, inclusive o que não é da PNAB" (AIC 3). O apoio integrado foi avaliado pelo grupo como uma estratégia pouco efetiva, cuja implementação não avançou, apesar de o DAB ter participado de movimentos institucionais nos territórios e na gestão interna da proposta. De modo geral, o AI da CGGAB desenvolveu-se paralelamente a esses movimentos, com pouca interlocução e integração com outros departamentos da SAS.

A gente discutiu pouco a rede, o integrado. [...] A gente começou a tentar, pelo menos se aproximar 
e não conseguiu construir essa visão um pouco mais integrada. Eno ministério, eu acho que a $A B$ ficou muito como a pauta de todo mundo. E aí, a gente não precisa olhar para mais nada, a gente só olha para $A B$. E a responsabilidade da $A B$ é resolver o problema de todo mundo. Resolver tudo. E aí também acaba falhando, porque a gente sabe que não é por aí, não vai dar conta, né? Então, sobrecarregou a gente, sendo chamado para tudo, de todo mundo. (AIC 16).

Não adianta ter apoio integrado, se as políticas não forem formuladas de maneira integrada. Quer dizer, um pouco adianta? Adianta, mas adianta pouco se a formulação, a decisão de algumas políticas não é feita pensando nisso, depois operar com o apoio integrado pode ser algo mais complicado de fazer. (D 2).

Na formulação da estratégia do AI no DAB/ MS, encontraram-se poucas prescrições do trabalho, enunciadas principalmente como diretrizes. A principal refere-se à construção de relações federativas de cooperação, e não de supervisão. Esperava-se que os apoiadores tivessem uma atuação proativa na oferta e implementação local das políticas e programas do departamento.

É mais horizontal, a gente não usou a palavra aqui, mas o apoio tem essa coisa mais horizontal, ele quebra uma lógica vertical de gestão, de construção de política, pressupõe uma lógica mais horizontal. (GF 2).

Os limites identificados na experiência de $\mathrm{AI}$ da CGGAB remetem à falta de clareza sobre o que é e como fazer o AI no DAB/MS.

Não sei se a gente tinha algum pensamento, não sei se hoje a gente tem [...] mas eu acho que ainda é algo completamente em construção. (AIC 1).

Eu acho que nossa maior dificuldade na CGGAB, era o ritmo louco de trabalho nosso. A gente tinha momentos de colegiado, sexta-feira. E era muito difícil da gente ter tempo de discutir o apoio em si. (AIC 14).
A instabilidade do vínculo empregatício dos apoiadores também surgiu como um nó crítico, responsável por uma rotatividade grande na equipe, intensificada na conjuntura política em que ocorreu o trabalho de campo, e que acarretou perdas significativas para a memória e o aprendizado institucional.

Não tinha muito essa cultura, do criar histórico, do deixar registro. Que é até um contrassenso, né? Justamente porque a rotatividade era grande [...] Até porque como a gente não tinha um vínculo muito seguro. (AIC 14).

Os apoiadores relataram problemas em conciliar as ofertas da gestão federal com as demandas e necessidades dos estados e municípios, revelando um tensionamento entre a diretriz de cooperação federativa e a finalidade instrumental de implementação de políticas e programas prioritários.

A gente às vezes vai também com pautas muito impostas, creio que aqui na $A B$, pelo tempo que eu tenho, procuro o máximo quebrar isso, mas, de alguma forma, acontece. (GF 2).

À parte esses aspectos, foram constatadas fragilidades operacionais, presentes principalmente na instabilidade do suporte logístico para realizar o apoio in loco; e nas dificuldades de acesso e compartilhamento de informações pelos apoiadores. A precariedade de condições estruturais para realização da atividade foi mais significativa no caso do AID.

[...] Como isso era imprescindível para o nosso processo de trabalho, a gente foi tensionando, [...] aí teve a perspectiva de começar a trabalhar com Dropbox, que era para compartilhar. (AID 4).

A partir de 2014, contudo, o suporte logístico tornou-se uma questão generalizada no AI devido às restrições vigentes para emissão de passagens e diárias no executivo federal. Tais dificuldades para realizar apoio in loco interferiram na construção do processo de 
trabalho, reduzindo as atividades de AIC nos territórios. Por sua vez, os AID também demonstravam deslocar-se com menor intensidade e capilaridade dentro dos estados apoiados, e suas atividades presenciais na equipe da coordenação foram drasticamente reduzidas.

Agora não mais [ida ao território]. [...] Agora a gente não sabe como vai ficar. [...] Não tem. Porque não tem passagem, não tem dinheiro, não tem... não tem autorização. (AIC 5).

No que tange ao acesso e à circulação da informação, o processo de AI evidenciou a concentração de informações técnicas em determinados atores e/ou setores institucionais. Essa foi uma fragilidade mais presente no AID devido à distância física, que acarretava maior dificuldade dos profissionais em manejar uma rede interna ao DAB e ao MS. "[...] hoje uma ferramenta disponivel para todo mundo é a nota técnica, que era algo só interno, que a gente não tinha acesso" (AID 3). O debate sobre estas limitações nas reuniões de colegiado do AI resultou na organização de um apoio matricial no departamento para obtenção das informações necessárias ao AI realizado na CGGAB.

Em contrapartida, também se observou a ausência de registro do processo de trabalho do AI, não obstante as diversas tentativas realizadas. Embora existissem alguns registros, como, por exemplo, relatórios, estes não foram feitos de modo sistemático. Os apoiadores em geral os realizavam sem haver um padrão estabelecido, sendo possível, inclusive, processos de apoio sem qualquer documentação. Esse aspecto dificultou a troca e compartilhamento de informações na equipe, e o acompanhamento das intervenções por parte da coordenação. Foi construído um sistema de informação para responder a essas dificuldades, porém, até o final do período estudado, ele não havia sido implantado.

[...] Eu acho que não tem, não tem essa cultura de memória institucional, né? [...] É... Acaba que não tem nada institucionalizado disso, né? E cada um acaba montando do seu jeito [...]. (AIC 9).

A dupla função dos AIC foi motivo de grande divergência entre os trabalhadores que participaram da pesquisa. Por um lado, ela foi percebida como aspecto limitante e concorrente com a lógica e com o modo operante necessário ao AI; por outro, foi compreendida como elemento de qualificação das políticas e programas. "Como tem frentes que dependem da coordenação para as coisas acontecerem, $o$ quanto o apoio às vezes fica negligenciado [...] isso é uma crise" (GF 1). A participação dos apoiadores como agentes responsáveis por pautas específicas no contexto do MS demonstrou ser um processo de educação permanente relevante para o domínio técnico do objeto de trabalho e para o desenvolvimento de habilidades políticas requeridas em seu exercício.

Nos resultados, o manejo das relações federativas foi particularmente destacado, em diferentes sentidos. A inserção e legitimação dos apoiadores nos territórios foi uma dimensão relevante e complexa das intervenções, e que requisita ser mais bem compreendida e desenvolvida na gestão federal. Os apoiadores evidenciaram que o fato de municípios acessarem diretamente o MS gerou conflitos, decorrentes do entendimento de que o fluxo pertinente para as comunicações entre entes federados deveria resguardar aos estados a atribuição de instância necessária de mediação. "Acho que isso [presença do apoiador no território] o estado não soube lidar muito, acabou gerando muitos conflitos" (AID 4). A grande rotatividade dos atores das gestões estaduais e municipais implicou um componente de descontinuidade administrativa e a necessidade de reconstrução permanente dos vínculos engendrados. As disputas e os conflitos em torno de interesses político-partidários emergiram como fator significativo na explicação de dificuldades de inserção e diálogo dos apoiadores nos territórios. "Eu acho a questão política é uma das maiores dificuldades, por exemplo, pra entrar em alguns espaços não é tão simples, né?" (AIC 10). 


\section{Discussão}

Na análise da experiência da CGGAB, destacam-se, dentre os efeitos positivos identificados, os vínculos e a rede sociotécnica articulada em função da PNAB. Como elemento de convergência, encontrou-se a percepção de que todo o trabalho do AI depende da qualidade do vínculo estabelecido. Nesse sentido, trata-se da conformação de uma relação social, em acepção weberiana, em que o sentido compartilhado se torna um elemento de configuração microssociológica da reciprocidade ${ }^{19}$. Nos casos em que isto não foi possível, os profissionais relataram a impossibilidade de instituir a relação de apoio, que acabava reduzida ao papel de uma referência técnica formal. Como pondera Wolfgang Schluchter ${ }^{20}$, é preciso compreender a importância dos componentes afetivos dessa relação, pouco explorados por Weber, mas que, no caso em análise, figuram determinantes da eficácia do AI. Nesse sentido, o trabalho de campo evidenciou que a rede sociotécnica configurada a partir da ação de apoio, ao mesmo passo que possuía uma finalidade racional clara (a implementação da PNAB), era alimentada pelas relações pessoais entre os atores, em um pêndulo que oscilava entre a dimensão político institucional das ações e o significado pessoal vivenciado na relação entre os agentes. Esse aspecto tornava os momentos informais da ação em território, como refeições e deslocamentos compartilhados, tão relevantes e cruciais como a agenda formal. Com isso, percebe-se a configuração de uma rede sociotécnica pouco visível do ponto de vista institucional, mas amplamente mobilizada e operada pelos agentes, inclusive por tecnologias virtuais, com múltiplas direcionalidades: tanto os apoiadores como os gestores locais a tinham como referência e a acessavam com finalidades práticas, revelando uma relação de cooperação e reciprocidade.

Outro ponto observado foi o potencial do AI para a qualificação da formulação em âmbito federal de políticas e programas de saúde. O diálogo estabelecido com os territórios alimentou com questionamentos e contraposições o trabalho normativo desenvolvido na gestão federal. O caso das unidades básicas fluviais, provavelmente, foi o exemplo mais claro disso, pois, a partir da presença dos apoiadores nos territórios da região Norte, as dúvidas, dificuldades e obstáculos vividos pelos gestores locais ganharam visibilidade no contexto do DAB/MS. Com isso, o AI provocou uma atualização normativa coerente com as especificidades locorregionais a que se destinavam as ações programáticas em tela. Esse efeito pôde ser observado de modo difuso no desenvolvimento e aperfeiçoamento dos programas prioritários geridos pelo departamento, para os quais a relação de apoio foi um vetor de qualificação. Nesse sentido, pode-se entrever que o AI impactou na ampliação do diálogo e no reconhecimento das especificidades locorregionais na gestão federal da $\mathrm{AB}$, incidindo no padrão institucional historicamente hegemônico no MS.

Os resultados de pesquisa evidenciam a centralidade das dimensões subjetivas na realização do $\mathrm{AI}$, revelando uma intensa requisição relacional do trabalho. As variabilidades implicadas no AI complexificam o recurso às normas antecedentes e demandam permanente avaliação e debate de valores na atividade em análise ${ }^{21,22}$. Suas características sinalizam que o AI efetivamente intervém na racionalidade gerencial hegemônica ${ }^{2}$, no sentido de promover uma gestão mais dialógica, modulada pelos efeitos produzidos pela intervenção, em oposição à prática corrente centrada no poder de estabelecer prescrições normativas. As relações e vínculos criados tornam-se tanto o contexto como os recursos de atuação dos apoiadores, e requerem acentuada capacidade de análise de conjuntura, delineamento estratégico e composição das ações, em diferentes planos, com diferentes sujeitos e coletivos.

$\mathrm{O}$ acesso e o uso de informações da gestão pública federal demonstraram ser um componente central do AI nesse âmbito, que intervém diretamente em sua legitimação, sendo, muitas vezes, manejado como meio de construção do vínculo. Pode-se afirmar que o apoio ampliou o acesso de seus interlocutores às informações técnicas da política de $\mathrm{AB}$, mas incidiu apenas 
pontualmente na construção de maior transparência e autonomia no uso destas informações, na medida em que qualificou a formulação de instrumentos normativos e outras ações institucionais. A atribuição de mediação do apoiador nesse acesso mostrou ser um dispositivo de ação, de que dificilmente estes profissionais podem prescindir na gestão federal. Entretanto, é preciso contextualizar que os resultados de pesquisa indicam ser essa uma característica da cultura organizacional do MS, já que, mesmo internamente, essa questão fez-se presente. Chama a atenção que, de forma recorrente, o compartilhamento de informações não fosse viabilizado por procedimentos institucionais. Este demonstrou ser um fator ao mesmo tempo limitante e validador no processo de trabalho dos apoiadores, já que, se por um lado restringia os recursos necessários à realização do trabalho, por outro, os próprios apoiadores tornavam-se as referências de acesso aos sujeitos e coletivos apoiados.

Com isso, o estudo possibilita problematizar o alcance e os horizontes do AI na democratização do Estado, tendo em vista que, se institui uma diferença ao ampliar o coeficiente dialógico da gestão, também opera mecanismos institucionais que atualizam a mediação no acesso às informações estratégicas da política pública. Nesse sentido, compartilha-se a perspectiva de Pierre Levy $^{23}$ a respeito da relevância dos fluxos informacionais e comunicacionais na configuração da inteligência coletiva contemporânea, constituindo condição de definição do que sejam o centro ou a periferia das redes sociais e institucionais, que, em última instância, podem ser uma outra definição do Estado.

A supremacia militar, a potência econômica, o brilho cultural estão diretamente relacionados à capacidade de controlar os fluxos informacionais, de conhecimento, de dinheiro e de mercadorias. O que é um centro? Um nó de fluxos. Um lugar geográfico ou virtual de onde está tudo 'próximo', acessível. O que é uma periferia? Uma extremidade de rede. Uma zona onde as interações são de curto alcance e de fraca densidade, onde os contatos de longe são difíceis e caros. O centro está densamente interconectado a ele próprio e ao mundo, a periferia está mal conectada a ela mesma e suas ligações com seu meio são controladas pelo centro ${ }^{23(146)}$.

Essas referências sobre a definição de centro e periferia são pertinentes à análise deste objeto de estudo, e permitem articular as dimensões microssociológicas identificadas na relação de AI às estruturas em que se situam, e que findam por atualizar, com maior ou menor potencial de diferenciação. A tarefa científica dos autores reside, justamente, na análise diferencial deste coeficiente. Pôde-se observar que o AI, ao ampliar as redes sociotécnicas da PNAB, aumentou os fluxos e trocas na gestão da política pública de saúde. Novos interlocutores passaram a ser reconhecidos, mobilizados e escutados, dispondo de mais informações técnicas relevantes para sua ação, mesmo quando esta permanecesse restrita ao contexto local. $\mathrm{O}$ interessante, e inovador, nos dados obtidos reside na intervenção operada na relação entre centro e periferia, instituída historicamente nas malhas estatais do contexto brasileiro.

Ainda que, de modo provisório e pontual, o AI produziu inteligibilidade, reconhecimento e legitimidade para as experiências locais, ao proporcionar condições de sua expressão e visibilidade. As posições institucionais de poder e acesso a recursos não foram, necessariamente, alteradas, mas a experiência daqueles historicamente inexistentes no circuito de poder do Estado Brasileiro tornou-se mais presente, como dado argumentativo, destarte mediado, na definição das políticas públicas a ele direcionadas. Na ocorrência desse fato, reside um potencial de diferenciação, em alguma medida capaz de publicizar o interesse e a ação estatal. Não se podem eliminar nessa análise as linhas de força e atualização das segmentações existentes, tampouco as resistências que este modo de diferenciação incita. Nesse plano, podem-se ler tanto a invisibilidade das questões estruturais atinente ao apoio como a resistência ativa que mobilizou internamente no MS. Ainda assim, 
sua pertinência reside nos vínculos que foi capaz de estabelecer, não obstante todas as mediações que os tornaram possíveis.

\section{Conclusões}

A estratégia de $\mathrm{AI}$ implementada no DAB/ MS engendrou e fortaleceu redes sociotécnicas, articuladas em função da PNAB, como dispositivo de mobilização e ação no Estado. É importante observar que esse efeito se revela condicionado à constituição de relações pessoais, limitadamente transferíveis. Tal aspecto não consiste em uma especificidade do apoio, porém, como a efetividade da estratégia depende da qualidade desse vínculo, infere-se que seu manejo tenha sido qualificado e institucionalizado pelo AI como recurso de gestão. Quanto a isso, o AI experimentado na AB no período em estudo demonstra operar com eficácia instituições historicamente arraigadas no Estado Brasileiro sem, contudo, necessariamente incidir em sua transformação, ainda que a porte como potencialidade. Em razão disso, pode-se conjecturar que, como modo de ação política por dentro da malha do Estado, tenha implicado uma ética de solidariedade no acesso a recursos e compartilhamento do processo decisório da política pública, produzindo efeitos com potenciais relevantes de intervir em sua democratização. Contudo, a necessidade de implementação do 'cardápio' que constitui a prioridade política da gestão demonstrou resultar em um tensionamento entre essa ética e as finalidades esperadas do apoio, em alguma medida mutuamente limitante e que requisita ser mais bem equacionada no desenho dessa estratégia de gestão.

\section{Colaboradores}

Guizardi FL (0000-0002-5086-4128)* participou do delineamento da pesquisa, trabalho de campo, codificação e análise do material produzido, redação do artigo e aprovação da versão final. Passeri L (0000-0001-5322-8736)* participou do trabalho de campo, codificação e análise do material produzido, redação de relatório de pesquisa. Lemos ASP (0000-0002-2483-4347)* participou do trabalho de campo, codificação e análise do material produzido, redação de relatório de pesquisa, revisão crítica do artigo e aprovação da versão final do artigo. Machado FRS (0000-00025028-8888)* participou do trabalho de campo, codificação e análise do material produzido, redação de relatório de pesquisa, revisão crítica do artigo e aprovação da versão final do artigo. 


\section{Referências}

1. Pereira Junior N. O apoio institucional no SUS. Os Dilemas da Integração Interfederativa e da Cogestão [dissertação]. Campinas, SP: Universidade Estadual de Campinas; 2013.

2. Campos GWS. Um método para análise e co-gestão de coletivos. A constituição do sujeito, a produção de valor de uso e a democracia em instituições: o método da roda. 2. ed. São Paulo: Hucitec, 2005.

3. Campos S. O anti-Taylor: sobre a invenção de um método para co-governar instituições de saúde produzindo liberdade e compromisso. Cad. Saúde Pública. 1998; 14(4):863-870.

4. Pereira N, Campos GWS. O apoio institucional no Sistema Único de Saúde (SUS): os dilemas da integração interfederativa e da cogestão. Interface (Botucatu). 2014; 18(supl1):895-908.

5. Oliveira EA, Cardoso GCP, Santos EM, et al. O apoiador local como ator estratégico na implementação do QualiSUS-Rede: engenheiros de conexão? Saúde debate. 2017; 41(esp):275-289.

6. Paulon SM, Pasche DF, Righi LB. Função apoio:da mudança institucional à institucionalização da mudança. Interface (Botucatu) 2014; 18(supl1):809-820.

7. Melo LMF. Apoio institucional em saúde: desafios para democratização na atenção básica [tese]. Natal: Universidade Federal do Rio Grande do Norte; 2015.

8. Cardoso JR. Cartografia das práticas de apoio na atenção primária à saúde na Regional Recanto das Emas, Distrito Federal [dissertação]. Brasília, DF: Faculdade de Ciências da Saúde; 2015.

9. Moura RH, Luzio CA. O apoio institucional como uma das faces da função apoio no Núcleo de Apoio à Saúde da Família (NASF): Para além das diretrizes. Interface (Botucatu). 2014; 18(supl1):957-970.
10. Gutiérrez AC. A co-produção da política estadual de atenção básica do Rio de Janeiro[dissertação]. Campinas: Universidade Estadual de Campinas; 2008.

11. Mattos TC. A função apoio e a gestão estadual: entre encontros, afetos, trilhas, armadilhas e dobras - cartografias da saúde no Rio de Janeiro. Rio de Janeiro: Fundação Oswaldo Cruz; 2013.

12. Falleiro LM. Experiências de Apoio Instucional no SUS: da teoria à prática. Porto Alegre: Rede Unida; 2014.

13. Righi L. Apoio matricial e institucional em Saúde: entrevista com Gastão Wagner de Sousa Campos. Interface (Botucatu). 2014; 18(supl1):1145-1150.

14. Trevisan LN, Junqueira LAP. Construindo o "pacto de gestão" no SUS: da descentralização tutelada à gestão em rede. Ciênc. Saúde Colet. 2007; 12(4):893902.

15. Klitzke DD. Apoio institucional na gestão da atenção básica no Brasil: um caminho possível? [dissertação]. Brasília, DF: Faculdade de Ciências da Saúde da UNB; 2013.

16. Vaz AC, Filho AN, Viadergorn B, et al. PMAQ e o apoio institucional: experiência da Coodenadoria Regional de Saúde Oeste. São Paulo: Secretaria Municipal de Saúde; 2015.

17. González Rey F. Epistemología Cualitativa y Subjetividad. La Habana: Editorial Pueblo y Educación; 1997.

18. Baremblitt GF. Compêndio de análise institucional e outras correntes: teoria e prática. 5. ed. Belo Horizonte: Instituto Felix Guattari; 2002.

19. Moraes LFR, Maestro Filho D, Dias DV. O paradigma weberiano da ação social: um ensaio sobre a compreensão do sentido, a criação de tipos ideais e suas 
aplicações na teoria organizacional. Rev Adm Contemp. 2003; 7(2):57-71.

20. Garcez EF. Weber, Schutz e a busca de sentido na ação social: uma análise comparativa. Em Tese. 2014; 11(1):1806-5023.

21. Durrive L, Schwartz Y. Glossário de Ergologia. Laboreal. 2008; 4(1):23-28.

22. Schwartz Y. A Comunidade científica ampliada e o regime de produção de saberes. Trab. educ. saúde. 2000; (7):38-46.
23. Levy P. A revolução contemporânea em matéria de comunicação. In: Guimarães C, Junior C, organizadores. Informação e democracia. Rio de Janeiro: EdUERJ; 2000. p. 137-161.

Recebido em 20/12/2018

Aprovado em 07/05/2019

Conflito de interesses: inexistente

Suporte financeiro: Conselho Nacional de Desenvolvimento

Científico e Tecnológico (CNPq). Financiamento da pesquisa por meio da Chamada Universal 